\title{
Effect of Nd:YAG Irradiation and Fluoride Application on Dentine Resistance to Erosion in Vitro
}

\author{
Ana Carolina Magalhães, Ph.D., ${ }^{1}$ Daniela Rios, Ph.D., ${ }^{2}$ \\ Maria Aparecida De Andrade Moreira Machado, Ph.D., ${ }^{3}$ Salete Moura Bonifácio Da Silva, Ph.D., ${ }^{3}$ \\ Rosane De Fátima Zanirato Lizarelli, Ph.D., ${ }^{4}$ Vanderlei Salvador Bagnato, Ph.D., ${ }^{4}$ \\ and Marília Afonso Rabelo Buzalaf, Ph.D. ${ }^{2}$
}

\begin{abstract}
Objective: In this paper we evaluated the effect of two fluoridated agents and Nd:YAG irradiation separately and in combination on dentine resistance to erosion. Background Data: The morphological changes in dentin induced by laser treatment may reduce the progression of erosive lesions. Due to the possibility of a synergistic effect of laser with fluoride, this study was conducted. Materials and Methods: Eighty bovine dentine samples $(4 \times 4 \mathrm{~mm})$ were randomly divided into eight groups, according to the following treatments: G1: untreated (control); G2: acidic phosphate fluoride gel (APF 1.23\%) for 4 min; G3: fluoride varnish (NaF 2.26\%) for 6 h; G4: $0.5 \mathrm{~W}$ Nd:YAG laser (250 $\mu$ sec pulse, $\left.10 \mathrm{~Hz}, 35 \mathrm{~J} / \mathrm{cm}^{2}, 30 \mathrm{sec}\right)$; G5: $0.75 \mathrm{~W}$ Nd:YAG laser $\left(52.5 \mathrm{~J} / \mathrm{cm}^{2}\right)$; G6: $1.0 \mathrm{~W}$ Nd:YAG laser $\left(70 \mathrm{~J} / \mathrm{cm}^{2}\right)$; G7: APF + $0.75 \mathrm{~W}$ Nd:YAG laser; and G8: NaF + $0.75 \mathrm{~W}$ Nd:YAG laser. After the treatments, half of each dentine surface was protected with nail varnish. The samples were stored in artificial saliva ( $30 \mathrm{~mL} / \mathrm{sample}$ ) for $24 \mathrm{~h}$ and submitted to four erosive 1-min cycles. Between the erosive attacks, the blocks were maintained in artificial saliva for $59 \mathrm{~min}$. The erosive wear was evaluated by profilometry. $R \boldsymbol{e}$ sults: The mean wear $( \pm \mathrm{SD}, \mu \mathrm{m})$ was: G1: $1.20 \pm 0.20$; G2: $0.47 \pm 0.06$; G3: $0.81 \pm 0.11$; G4: $1.47 \pm 0.32$; G5: $1.52 \pm$ 0.24; G6: $1.49 \pm$ 0.30; G7: $0.49 \pm$ 0.11; and G8: $1.06 \pm 0.31$ (Tukey's test, $p<0.05$ ). Conclusions: Laser irradiation was not able to reduce dentine erosion. However, fluoride application was able to increase the dentine's resistance to erosion, and APF showed better results than fluoride varnish.
\end{abstract}

\section{Introduction}

C ERVICAl hypersensitivity is a COMMON PROBlem in dentistry, and is related to the exposure of root dentine and consequent dentin wear, which can be induced by erosion or abrasion. ${ }^{1}$ Dental erosion is thought to be the most important etiological factor, as increased consumption of acidic foods and beverages can be observed. ., $^{2}$

Initially, the erosive wear of dentine is characterized by demineralization of the interface between the intertubular and peritubular dentin. With increasing exposure time, the erosive attack results in a hollowing and funneling of the dentinal tubules. Finally, the peritubular dentin is completely dissolved. The erosive demineralization results in the exposure of an outer layer of fully demineralized organic matrix, followed by a partly demineralized zone, until the sound inner dentin is reached. ${ }^{4,5}$ The high number of open and widened dentinal tubules may allow fluid movement, which stimulates the nerve endings located in the predentine and the odontoblast layer. As a consequence, painful hypersensitivity of the tooth may occur, especially during acid exposure. ${ }^{6}$

As it is difficult to control all of the etiological factors contributing to dental erosion, such as the intake of acidic beverages or other damaging agents, ${ }^{7}$ many strategies have been developed to prevent or arrest dentine erosion and consequently, dentine hypersensitivity. Studies have shown that the application of fluoride $\mathrm{e}^{8,9}$ and Nd:YAG laser treatment ${ }^{10}$ can promote dentinal tubule occlusion, which in turn prevents dentinal fluid movement. The beneficial effect of fluoride is associated with the formation of a calcium fluoridelike precipitate, which may occlude the dentinal tubules. ${ }^{11}$ On the other hand, the ability of lasers to melt the dentin, reduce the tubular diameter, or seal the opened dentinal

${ }^{1}$ Department of Child and Social Dentistry, School of Dentistry of Araçatuba, São Paulo State University, Araçatuba, ${ }^{2}$ Department of Biological Sciences, Bauru School of Dentistry, University of São Paulo, ${ }^{3}$ Department of Pediatric Dentistry, Orthodontic and Public Health, Bauru School of Dentistry, Bauru, and ${ }^{4}$ Department of Physics and Materials Science, Institute of Physics of São Carlos, São Carlos, Brazil. 
tubules, may be a potential tool for treatment of hypersensitivity. ${ }^{10,12-14}$

The morphological changes induced by laser treatment of dental surfaces, such as the reduction of the carbonate content ${ }^{15}$ and closure of dentinal tubules, ${ }^{10}$ might also reduce the progression of erosive lesions. Due to the possibility of a synergistic effect between different treatments, it is speculated that it may be possible to increase their beneficial effects using the combination of fluoride application and laser irradiation. Therefore, the aim of the present in vitro study was to evaluate the effect of two fluoridated agents (gel and varnish) and Nd:YAG irradiation (0.5, 0.75, and $1.0 \mathrm{~W})$ separately and in combination on dentine's resistance to erosion.

\section{Materials and Methods}

\section{Dentine sample preparation}

Eighty root dentine samples $(4 \times 4 \times 3 \mathrm{~mm})$ were prepared from extracted bovine incisors, which were previously stored in $2 \%$ formaldehyde solution ( $\mathrm{pH} 7.0$ ) for $30 \mathrm{~d}$ at room temperature. One sample was cut from each root using an IsoMet Low Speed Saw (Buehler Ltd., Lake Bluff, IL, USA) with two diamond disks (Extec Corp., Enfield, CT, USA), which were separated by a $4-\mathrm{mm}$ spacer. The labial dentine surfaces were ground flat with water-cooled abrasive discs (320-, 600-, and 1200-grit $\mathrm{Al}_{2} \mathrm{O}_{3}$ papers; Buehler, Lake Bluff, IL, USA) and polished with felt paper and diamond spray ( $1 \mu \mathrm{m}$; Buehler). This procedure resulted in removal of a layer of dentine about $200 \mu \mathrm{m}$ deep. The surface microhardness was determined by performing five indentations (Knoop diamond, 10 g, 5 sec, HMV-2000; Shimadzu Corp., Tokyo, Japan) in the center of the dentine surface, for selection and randomized distribution purposes. Dentine samples with microhardness ranging from 34-60 Knoop hardness $(\mathrm{KHN})(45.90 \pm 6.33 \mathrm{KHN})$ were randomly distributed into eight groups ( $n=10$ each): G1: untreated (controls); G2: acidic phosphate fluoride gel (APF; $1.23 \%$ fluoride) for $4 \mathrm{~min}$; G3: fluoride varnish (NaF; $2.26 \%$ fluoride) for $6 \mathrm{~h}$; G4: $0.5 \mathrm{~W}$ Nd:YAG laser (250 $\mu$ sec pulse, $\left.10 \mathrm{~Hz}, 35 \mathrm{~J} / \mathrm{cm}^{2}, 30 \mathrm{sec}\right)$; G5: $0.75 \mathrm{~W}$ Nd:YAG laser (52.5 J/ $\mathrm{cm}^{2}$ ); G6: $1.0 \mathrm{~W}$ Nd:YAG laser $\left(70 \mathrm{~J} / \mathrm{cm}^{2}\right) ; \mathrm{G} 7: \mathrm{APF}+0.75 \mathrm{~W} \mathrm{Nd}$ :YAG laser; and G8: $\mathrm{NaF}+0.75 \mathrm{~W}$ Nd:YAG laser.

\section{Experimental procedure}

In group 1, the dentine samples were not treated and served as controls. In group 2, the acidic phosphate fluoride gel (pH 3.5; Flugel, DFL, Rio de Janeiro, Brazil) was applied to each dentine surface with a microbrush and left on for 4 min. After the time elapsed, the excess gel was removed with cotton swabs. In group 3, the fluoride varnish (pH 4.5; Duraphat, Colgate, São Paulo, Brazil) was applied in a thin layer with a microbrush to each dentine surface. After $6 \mathrm{~h}$, the varnish was carefully removed using acetone and a scalpel blade. ${ }^{16,17}$

In groups 4, 5, and 6, the samples were irradiated with an Nd:YAG laser (Twinlight; Fotona Medical Lasers, Ljublijana, Slovenia), in contact and non-contact mode, perpendicularly to the sample via a quartz fiber with a diameter of $300 \mu \mathrm{m}$. This laser system has a pulse length of $250 \mu \mathrm{sec}$ and repetition rate from $5-10 \mathrm{~Hz}$. The laser device was fixed above a horizontally moving table, which allowed scanning movements in four directions (mesial-distal and apical-occlusal; $5 \times 5 \mathrm{~mm}$ ) with uniform velocity for $30 \mathrm{sec}$ for each application. For laser application, the samples were moved by the table, allowing the fixed laser beam to scan the entire surface. The irradiation conditions for the laser groups were: G4: 0.5 W Nd:YAG laser $\left(250 \mu \mathrm{m}, 10 \mathrm{~Hz}, 35 \mathrm{~J} / \mathrm{cm}^{2}\right) ; \mathrm{G} 5: 0.75$ W Nd:YAG laser (52.5 J/ $\left.\mathrm{cm}^{2}\right)$; and G6: $1.0 \mathrm{~W} \mathrm{Nd:YAG} \mathrm{laser}$ $\left(70 \mathrm{~J} / \mathrm{cm}^{2}\right)$.

In group 7, the samples were first treated with APF as described above, and afterwards they were irradiated with the Nd:YAG laser $(0.75 \mathrm{~W})$. Group 8 samples were first treated with fluoride varnish as described above, and afterwards were irradiated with the Nd:YAG laser $(0.75 \mathrm{~W})$.

After all of the treatments, two layers of nail varnish were applied to half of the surface of the dentine of each sample in order to maintain reference surfaces for lesion depth determination.

For $24 \mathrm{~h}$, the samples were kept in artificial saliva (30 $\mathrm{mL} /$ sample), and then were immersed in Sprite Light ${ }^{\circledR}$ (30 $\mathrm{mL}$ /sample; Coca-Cola Co., Spal, Porto Real, RJ, Brazil) for $1 \mathrm{~min}$, four times at room temperature. ${ }^{18}$ Between the erosive attacks, the samples were kept in artificial saliva for 59 min. The Sprite Light ( $\mathrm{pH} 2.87$ ) had a buffering capacity of $0.375 \pm 0.01$, which is equivalent to $0.375 \mathrm{~mL}$ of $0.2 \mathrm{M}$ $\mathrm{NaOH} / 3 \mathrm{~mL}$ beverage, for an increase of one $\mathrm{pH}$ unit. ${ }^{18}$ The composition of the artificial saliva was: $1.5 \mathrm{mM} \mathrm{Ca}\left(\mathrm{NO}_{3}\right)_{2} \cdot 4$ $\mathrm{H}_{2} \mathrm{O}, 0.9 \mathrm{mM} \mathrm{NaH}_{2} \mathrm{PO}^{4} \cdot 2 \mathrm{H}_{2} \mathrm{O}, 150 \mathrm{mM} \mathrm{KCl}, 0.1 \mathrm{M}$ Tris buffer, 0.03 ppm fluoride, $\mathrm{pH} 7.0{ }^{19}$

\section{Wear assessment}

The dentine wear was determined by profilometry in relation to the reference surface, which was previously protected by nail varnish (Hommel Tester T1000; Hommel Tech, VS, Schwenningen, Germany). The nail varnish on the reference surfaces was carefully removed with acetone-soaked cotton. ${ }^{20}$ Five readings were taken on each sample by scanning from the reference portion to the exposed surface. The lowest area of the eroded area compared to the reference surface was calculated by the software of the device and was considered as wear. The mean values of five readings for each group were averaged.

\section{Statistical analysis}

We used GraphPad Instat for Windows (GraphPad, San Diego, CA, USA) software to perform the statistical analysis. The assumptions of equality of variances and normal distribution of errors were checked for all the variables tested. Since the assumptions were satisfied, ANOVA and Tukey's tests were carried out for statistical comparisons and statistical significance was set at $p<0.05$.

\section{Results}

Table 1 shows the mean wear $(\mu \mathrm{m} \pm \mathrm{SD})$ for each group. Significantly higher dentine wear $(1.20-1.52 \mu \mathrm{m})$ was recorded for groups G5 (0.75 W laser), G1 (control), G4 (0.5 W laser), and G6 (1 W laser). Group G5 significantly differed from G1, G4, and G6, which did not differ significantly from one another. Group G8 (varnish + laser) had less wear compared to the other laser groups G4, G5, and G6 $(p<0.05)$, 
TABle 1. Dentin Wear $(\mu \mathrm{M} \pm \mathrm{SD})$ FOR EACH EXPERIMENTAL GROUP

\begin{tabular}{ll}
\hline Group & Wear $(\mu m)$ \\
\hline G1: Control & $1.20 \pm 0.20^{\mathrm{a}, \mathrm{c}}$ \\
G2: APF gel & $0.47 \pm 0.06^{\mathrm{b}}$ \\
G3: NaF varnish & $0.81 \pm 0.11^{\mathrm{c}}$ \\
G4: 0.5 W Nd:YAG laser & $1.47 \pm 0.32^{\mathrm{a}}$ \\
G5: 0.75 W Nd:YAG laser & $1.52 \pm 0.24^{\mathrm{d}}$ \\
G6: $1.0 \mathrm{~W}$ Nd:YAG laser & $1.49 \pm 0.30^{\mathrm{a}}$ \\
G7: APF gel + 0.75 W Nd:YAG laser & $0.49 \pm 0.11^{\mathrm{b}}$ \\
G8: NaF varnish + 0.75 W Nd:YAG laser & $1.06 \pm 0.31^{\mathrm{c}, \mathrm{e}}$
\end{tabular}

Values followed by the same superscript letters indicate statistical significance $(p<0.05)$.

but it was also similar to controls. Only G2 (APF), G3 (varnish), and G7 (APF + laser) had significantly less dentine wear $(0.47-0.81 \mu \mathrm{m})$ compared to controls $(p<0.05)$. However, groups G2 and G7 (APF) were not significantly different from each other, but showed better results compared to group G3 (fluoride varnish) $(p<0.05)$.

\section{Discussion}

Fluoride treatment is an established tool in the prevention of demineralization of dental hard tissues. ${ }^{11,21}$ The most common fluoridated agents in clinical use are gels and varnishes. As fluoride varnishes exhibit a better capability to adhere to the tooth surface than fluoride gels, the fluoride varnish was applied for $6 \mathrm{~h}$, while the gel was applied for only $4 \mathrm{~min}$ in the present study. However, the efficacy of fluoride varnishes and gels in decreasing demineralization and enhancing remineralization of dental hard tissues is similar. ${ }^{22,23}$

On the other hand, the protective effects of laser irradiation of enamel and dentine from demineralization have gained increasing attention in recent years. Several types of lasers, such as ruby, $\mathrm{CO}_{2}, \mathrm{Nd}: \mathrm{YAG}$, and argon, with different operational modes and energy outputs have been investigated. ${ }^{24}$ Most of the studies of the effects of laser irradiation on dental hard tissue demineralization have been conducted in vitro using the Nd:YAG laser, due to its ease of application in the oral cavity. ${ }^{24}$ However, microscopic analyses have been used in most studies that tested this laser, ${ }^{12,25,26}$ and this method is unable to quantify the loss of dental hard tissue.

Naylor et al. ${ }^{12}$ showed that irradiation with the Nd:YAG laser produces obliteration of and reduction in the numbers of dentinal tubules, thus modifying its original structure. The authors suggested that dentine irradiated with $0.6 \mathrm{~W}$ of $\mathrm{Nd}$ :YAG laser energy had a higher resistance to acidic beverages such as colas and passion fruit juice, but they did not evaluate erosion quantitatively. Kimura et al. ${ }^{27}$ showed that $\mathrm{Nd}$ :YAG irradiation (1-5 J/ $\mathrm{cm}^{2}$ ) induced morphological changes (melting and smoothing) of the dentine's surface. However, Nd:YAG irradiation was unable to protect dentine against caries, as shown by scattering light microscopy. This result indicates that the effect of laser irradiation is limited to the surface. This observation underlines the need for studies evaluating the effects of laser irradiation quantitatively.

In the present study, bovine dentine was used as a substitute for human teeth, as has been done in several previ- ous studies. ${ }^{25,28,29}$ Despite the morphological differences between bovine and human substrates, bovine dentine offers similar acid resistance to that of human dentine in situ. ${ }^{30}$ With regard to the polished dentine samples we used in the present study, it must also be considered that polished samples have been shown to be more susceptible to demineralization than natural surfaces, as the fluoride-rich enamel surface layer is removed by the polishing. ${ }^{31}$ This aspect has to be carefully considered when the results are extrapolated to an in-vivo situation. Despite these limitations, in vitro studies have to be conducted before clinical testing of new methods can begin.

The type of laser and the intensity used were chosen in accordance with previous studies. ${ }^{12,26,27,32}$ The samples were briefly eroded $(60 \mathrm{sec})$ by a common soft drink containing citric acid to simulate the sipping or drinking of an erosive beverage. The artificial saliva we used allows rehardening of the samples between erosive challenges. The profilometry technique we used in the present study is a quantitative method that is able to measure dentine loss induced by the cyclic $\mathrm{pH}$ changes, ${ }^{33}$ thus reflecting the cumulative effect of the erosive challenges.

In this study, we found that laser irradiation was unable to reduce erosive dentine wear. The efficacy of the laser irradiation may have been affected by many factors, such as the laser wavelength and energy output, and dentine surface conditions (dry or wet). The proper laser wavelength and energy output may change the dentine's surface and reduce the progression of demineralization. ${ }^{12}$ Regarding the energy output, it can be assumed that the high laser power used in this study (0.5-1 W) may induce cracks and fissures instead of melting and resolidification of the dentinal surface. This cracked surface may be more susceptible to acid challenge. ${ }^{24}$ Lan et al. ${ }^{26}$ showed that energy levels inducing crater formation by the Nd:YAG laser ranged from 100-150 mJ, which is much lower than the energy levels we used in the present study. Similarly to the results of the present study, Tsai et al. ${ }^{24}$ found no protective effect of Nd:YAG laser treatment on enamel demineralization in vitro. The pulsed Nd:YAG laser $\left(83.33 \mathrm{~J} / \mathrm{cm}^{2}\right)$ was unable to increase the enamel's resistance to acid challenge (lactate buffer solution, $\mathrm{pH} 4.5$, for 24 and $72 \mathrm{~h}$ ), as shown by calcium analysis and polarized light microscopy. Therefore, further studies are required to test the effects of lower laser power levels $(<0.5 \mathrm{~W})$ on dental erosion. To understand the mechanism of action of $\mathrm{Nd}$ :YAG irradiation, it is also important to analyze the superficial and structural changes of laser-irradiated dentine at different laser power levels.

Besides crack formation, thermal changes caused by elevations in temperature in the irradiated region may cause pulp damage in the clinical setting. ${ }^{26}$ White et al. ${ }^{32}$ suggested using laser power levels no higher than $1 \mathrm{~W}$ to avoid these thermal changes. According to Kimura et al., ${ }^{27}$ the intrapulpal temperature increases may exceed $5.5^{\circ} \mathrm{C}$ during irradiation at energy densities of $2.0 \mathrm{~J} / \mathrm{cm}^{2}$. However, the power levels $(0.5-1.0 \mathrm{~W})$ and the type of laser system (nanosecond pulse) used in the present study may not cause pulpal heating to damaging levels.

In contrast to the laser treatment and in accordance with previous studies, fluoride application was effective in increasing the dentine's resistance to erosive losses. ${ }^{34,35}$ As erosive lesions do not cause subsurface lesions that make rem- 
ineralization possible, the action of fluoride is mainly attributable to precipitation of a calcium fluoride-like material on dental surfaces. ${ }^{34,35}$ Although the fluoride concentration as well as the time of contact is lower for the gel (4 min) compared to the varnish $(6 \mathrm{~h})$, the APF gel (1.23\% fluoride, $\mathrm{pH}$ 3.5) had better results compared to those of the varnish (2.26\% fluoride, $\mathrm{pH} 4.5)$. This may be explained by their differing $\mathrm{pH}$ levels. It is well known that the formation of the calcium fluoride reservoir is increased under acidic compared to neutral $\mathrm{pH}$ levels. ${ }^{11,21}$

\section{Conclusion}

With the protocol we used in this study, laser irradiation was unable to reduce beverage-induced dentinal erosion. However, fluoride application was able to increase the dentine's resistance to erosion, and the acidic phosphate fluoride gel achieved better results than the fluoride varnish.

\section{Acknowledgments}

The authors thank Prof. Rafael Lia Mondelli for the use of the profilometer, and Master Student in Electric Engineering Mardoqueu Martins Costa for the use of his device to standardize our laser irradiation scanning protocol.

\section{Disclosure Statement}

No conflicting financial interests exist.

\section{References}

1. Addy, M., and Shellis, R.P. (2006). Interaction between attrition, abrasion and erosion in tooth wear. Monogr. Oral Sci. 20, 17-31.

2. Lussi, A., Jaeggi, T., and Zero, D. (2004). The role of diet in the etiology of dental erosion. Caries Res. 38, 34-44.

3. Lussi, A. (2006). Erosive tooth wear-a multifactorial condition of growing concern and increasing knowledge. Monogr. Oral Sci. 20, 1-8.

4. Kinney, J.H., Balooch, M., Haupt, D.L. Jr., Marshall, S.J., and Marshall, G.W. Jr. (1995). Mineral distribution and dimensional changes in human dentin during demineralization. J. Dent. Res. 74, 1179-1184.

5. Meurman, J.H., Drysdale, T., and Frank, R.M. (1991). Experimental erosion of dentine. Scand. J. Dent. Res. 99, $457-462$.

6. Addy, M., Absi, E.G., and Adams, D. (1987). Dentin hypersensitivity. The effects in vitro of acids and dietary substances on root-planed and burred dentin. J. Clin. Periodontol. 14, 274-279.

7. Johansson, A.K., Lingstrîm, P., Imfeld, T., and Birkhed, D. (2004). Influence of drinking method on tooth-surface $\mathrm{pH}$ in relation to dental erosion. Eur. J. Oral Sci. 112, 484-489.

8. White, D.J., Lawless, M.A., Fatade, A., et al. (2007). Stannous fluoride/sodium hexametaphosphate dentifrice increases dentin resistance to tubule exposure in vitro. J. Clin. Dent. $18,55-59$.

9. Ritter, A.V., Dias, W.L., Miguez, P., Caplan, D.J., and Swift, E.J. Jr. (2006). Treating cervical dentin hypersensitivity with fluoride varnish: a randomized clinical study. J. Am. Dent. Assoc. 137, 1013-1020.

10. Lan, W.H., and Liu, H.C. (1996). Treatment of dentin hypersensitivity by Nd:YAG laser. J. Clin. Laser Med. Surg. 14, 89-92.
11. ten Cate, J.M. (1997). Review on fluoride, with special emphasis on calcium fluoride mechanisms in caries prevention. Eur. J. Oral Sci. 105, 461-465.

12. Naylor, F., Aranha, A.C., Eduardo, C.P., Arana-Chavez, V.E., and Sobral, M.A.P. (2006). Micromorphological analysis of dentinal structure after irradiation with Nd:YAG laser and immersion in acidic beverages. Photomed. Laser Surg. 24, 745-752.

13. Yonaga, K., Kimura, Y., and Matsumoto, K. (1999). Treatment of cervical dentin hypersensitivity by various methods using pulsed Nd:YAG laser. J. Clin. Laser Med. Surg. 17, 205-210.

14. Ciaramicoli, M.T., Carvalho, R.C., and Eduardo, C.P. (2003). Treatment of cervical dentin hypersensitivity using neodymium: yttrium-aluminum-garnet laser. Clinical evaluation. Laser Surg. Med. 33, 358-362.

15. Nelson, D.G.A., Wefel, J.S., Jongebloed, W.L., and Featherstone, J.D.B. (1987). Morphology, histology and crystallography of human dental enamel treated with pulsed low-energy infrared laser radiation. Caries Res. 21, 411-426.

16. Delbem, A.C.B., Bergamaschi, M., Sassaki, K.T., and Cunha, R.F. (2006). Effect of fluoridated varnish and silver diamine fluoride solution on enamel demineralization: $\mathrm{pH}$-cycling study. J. Appl. Oral Sci. 14, 88-92.

17. Vieira, A., Lugtenborg, M., Ruben, J.L., and Huysmans, M.C. (2006). Brushing abrasion of eroded bovine enamel pretreated with topical fluorides. Caries Res. 40, 224-230.

18. Sales-Peres, S.H.C., Magalhães, A.C., Machado, M.A.A.M., and Buzalaf, M.A.R. (2007). In vitro evaluation of variables related to the erosive potential of five soft drinks. Eur. J. Dent. 1, 10-13.

19. Vieira, A.E.M., Delbem, A.C.B., Sassaki, K.T., Rodrigues, E., Cury, J.A., and Cunha, R.F. (2005). Fluoride dose response in $\mathrm{pH}$-cycling models using bovine enamel. Caries Res. 39, 514-520.

20. Attin, T., Buchalla, W., Gollner, M., and Hellwig, E. (2000). Use of variable remineralization periods to improve the abrasion resistance of previously eroded enamel. Caries Res. $34,48-52$.

21. ten Cate, J.M. (1999). Current concepts on the theories of the mechanism of action of fluoride. Acta. Odontol. Scand. 57, 325-329.

22. Vieira, A., Jager, D.H., Ruben, J.L., and Huysmans, M.C. (2007). Inhibition of erosive wear by fluoride varnish. Caries Res. 41, 61-67.

23. Seppa, L. (1988). Effects of a sodium fluoride solution and a varnish with different fluoride concentrations on enamel remineralisation in vitro. Scand. J. Dent. Res. 96, 304-309.

24. Tsai, C.L., Lin, Y.T., Huang, S.T., and Chang, H.W. (2002). In vitro acid resistance of $\mathrm{CO} 2$ and $\mathrm{Nd}$ :YAG laser-treated human tooth enamel. Caries Res. 36, 423-429.

25. Bachmann, L., Craievich, A.F., and Zezell, D.M. (2004). Crystalline structure of dental enamel after Ho:YLF laser irradiation. Arch. Oral Biol. 49, 923-929.

26. Lan, W.H., Chen, K.W., Jeng, J.H., Lin, C.P., and Lin, S.K. (2000). A comparison of the morphological changes after $\mathrm{Nd}-\mathrm{YAG}$ and $\mathrm{CO}_{2}$ laser irradiation of dentin surfaces. J. Endod. 26, 450-453.

27. Kimura, Y., Wilder-Smith, P., Arrastia-Jitosho, A.M., Liaw, L.H., Matsumoto, K., and Berns, M.W. (1997). Effects of nanosecond pulsed Nd:YAG laser irradiation on dentin resistance to artificial caries-like lesions. Laser Surg. Med. 20, $15-21$.

28. Hara, A.T., Ando, M., Gonzalez-Cabezas, C., Cury, J.A., Serra, M.C., and Zero, D.T. (2006). Protective effect of the 
dental pellicle against erosive challenges in situ. J. Dent. Res. 85, 612-616.

29. Hannig, C., Becker, K., Hausler, N., Hoth-Hannig, W., Attin, T., and Hannig, M. (2007). Protective effect of the in situ pellicle on dentin erosion-an ex vivo pilot study. Arch. Oral Biol. 52, 444-449.

30. Hara, A.T., Queiroz, C.S., Paes Leme, A.F., Serra, M.C., and Cury, J.A. (2003). Caries progression and inhibition in human and bovine root dentine in situ. Caries Res. 37, 339-344.

31. Ganss, C., Klimek, J., and Schwarz, N. (2000). A comparative profilometric in vitro study of the susceptibility of polished and natural human enamel and dentine surfaces to erosive demineralization. Arch. Oral Biol. 45, 897-902.

32. White, J.M., Goodis, H.E., Setcos, J.C., Eakle, S., Hulscher, B.E., and Rose, C.L. (1993). Effects of pulsed Nd:YAG laser energy on human teeth: a three-year follow-up study. J. Am. Dent. Assoc. 124, 45-51.

33. Attin T. (2006). Methods for assessment of dental erosion. Monogr. Oral Sci. 20, 152-172.
34. Ganss, C., Klimek, J., SchÑffer, U., and Spall, T. (2001). Effectiveness of two fluoridation measures on erosion progression in human enamel and dentine in vitro. Caries Res. 35, 325-330.

35. Ganss, C., Klimek, J., Brune, V., and Schumann, A. (2004). Effects of two fluoridation measures in erosion progression on enamel and dentine in situ. Caries Res. 38, 561-566.

Address reprint requests to: Professor Marília Afonso Rabelo Buzalaf, Ph.D.

Department of Biological Sciences Bauru School of Dentistry University of São Paulo Al. Octavio Pinheiro Brissola 9-75

Bauru, SP, Brazil 17012-910

E-mail: mbuzalaf@fob.usp.br 